\title{
Pelatihan Modul Ajar Robotika Berbasis Visual Basic Di SMP Swasta Assyuhada Medan
}

\author{
Trainning of Robotic Learning Visual Basic Module \\ In SMP Swasta Assyuhada Medan \\ Fadhillah Azmi ${ }^{1}$, Juanda Hakim Lubis ${ }^{2)}$ \& N P Dharshinni ${ }^{3)}$
}

1,3)Prodi Teknik Informatika, Fakultas Teknik dan Ilmu Komputer, Universitas Prima Indonesia, Indonesia

2) Prodi Teknik Informatika, Fakultas Teknik, Universitas Medan Area, Indonesia Diterima: Juli 2019 ; Disetujui: Agustus 2019 ; Dipublish: September 2019

\section{*Corresponding Email : azmi.fadhillah007@gmail.com}

\section{Abstrak}

Guru SMP Swasta Assyuhada Medan pada umumnya mengalami kesulitan dalam menerapkan praktikum dan pengaplikasian pada mata pelajaran muatan lokal elektronika yang bisa dinilai sebagai karya inovatif dan pengembangan untuk anak didik. Keadaan ini disebabkan karena para guru masih minimnya dana langsung apabila membeli atau memfasilitasi peralatan yang digunakan. Tujuan kegiatan ini agar peserta pelatihan guru-guru SMP Swasta Assyhada Medan dalam menjalankan tugasnya memiliki kemampuan teknik simulasi media pembelajaran sebagai karya inovatif sehingga mampu meniningkatkan keprofesionalan secara berkelanjutan. Metode yang digunakan berupa pelatihan modul pembelajaran robotika dengan menggunakan simulasi dari Visual Basic. Kegiatan pengabdian kepada masyarakat ini diharapkan berhasil agar pada akhir kegiatan semua peserta pelatihan memiliki pengetahuan dan keterampilan tentang memberikan praktikum ke anak didik sehingga anak didika dapat ide kreativ yang lebih.

Kata Kunci: Modul, Robotika, Visual Basic.

\section{Abstract}

The teachers of SMP Swasta Assyuhada Medan have difficulty in applying practicum and application to local electronic content subjects that can be assessed as innovative work and development for students. This situation is caused by teachers who still lack direct funds when buying or facilitating equipment used. The purpose of this activity is that the trainning of SMP Swasta Assyuhada Medan in carrying out their duties have the capability of learning media simulation techniques as innovative works so as to increase professionalism on an ongoing basis. The method used is in the form of training robotics learning modules using simulations from Visual Basic. This community service activity is expected to succeed so that at the end of the activity all the training participants have the knowledge and skills about giving lab work to students so that the children can get more creative ideas.

Keywords: Module, Robotic, Visual Basic

How to cite : Azmi, F. Lubis, J,H. \& Dharshinni N,P. (2019). Pelatihan Modul Ajar Robotika Berbasis Visual Basic Di SMP Swasta Assyuhada Medan. Pelita Masyarakat : Jurnal Pengabdian Masyarakat 1(1) :24-29 


\section{PENDAHULUAN}

Kota Medan merupakan ibu kota dari Provinsi Sumatera Utara. Kota Medan selain sebagai kota wisata, kota industri, juga berkembang sebagai kota pendidikan. Universitas Negeri Medan (Unimed) yang terletak di tengah kota Medan memiliki Program Studi S1 Perguruan di Teknik di bawah naungan Fakutas Pendidikan Teknik yang mana mempersiapkan lulusan tenaga Profesional yang dapat menjadi pendidik, pengelola, peneliti, pengembang di lembaga pendidikan.

Tingkat Pendidikan Guru di Kota Medan bervariasi, ada sebagian yang masih lulusan S1, lulusan S1 di luar pendidikan keguruan, bahkan ada yang lulusan S2. Guru sebagai tenaga pendidik profesional dituntut kreativitasnya untuk mengembangkan karya inovatif untuk Proses Belajar Mengajar (PBM). Salah satu karya inovatif yang banyak dibuat guru adalah membuat/memodifikasi alat pelajaran yang dapat digunakan sebagai media pembelajaran dalam melaksanakan tugas mengajar.

Dari hasil observasi awal dan wawancara singkat dengan beberapa guru dan kepala SMP di SMP Sasta Assyuhada Medan menunjukkan bahwa para guru SMP pada umumnya mengalami kesulitan dalam membuat dan mengaplikasikan praktikum langsung ke anak didik dengan modifikasi media pembelajaran yang bisa dinilai sebagai karya inovatif untuk syarat kenaikan pangkat dalam pengembangan profesi mereka. Keadaan ini disebabkan karena para guru pamong belum memiliki wawasan dan keterampilan yang memadai tentang teknis penerapnnya.

Cara yang terbaik untuk menyelesaikan masalah yang dihadapi oleh para guru SMP Sawsta Assyuhada Medan dilakukan melalui Pelatihan Modul Pembelajaran Robotika dengan menggunakan Visual Basic sebagai simulasi pembelajaran yang inovatif.

Keterampilan pembuatan simulasi laporan karya inovatif yang dimiliki guru meningkatkan profesionalitas guru dan merangsang kreativitas mahasiswa yang pada akhirnya akan menunjang tercapainya peningkatan kwalitas pendidikan.

Tujuan kegiatan ini diharapkan semua peserta pelatihan memiliki kemampuan teknik pembuatan modul ajar khususnya dibidang mata pelajaran yang diampu.

\section{METODE PELAKSANAAN}

Secara garis besar, tahapan keseluruhan penelitian adalah sebagai berikut : 
1. Tahap persiapan. Aktifitas penelitian dititikberatkan pada studi literatur, pengayaan konten dan konteks penelitian, dan survey lapangan. Dari tahap ini diperoleh datadata awal, yakni pengertian, parameter-parameter.

2. Tahap perancangan. Pada tahap ini dilakukan perancangan sistem meliputi :

a. Pemilihan materi mata pelajaran yang digunakan.

b. Perancangan simulasi dengan menggunakan Visual Basic.

3. Tahap Implementasi dan Pengujian. Tahap ini dimaksudkan sebagai langkah pengujian kinerja simulasi.

4. Tahap penyelesaian. Tahap dimana catatan kegiatan dan hasil penelitian didokumentasikan.

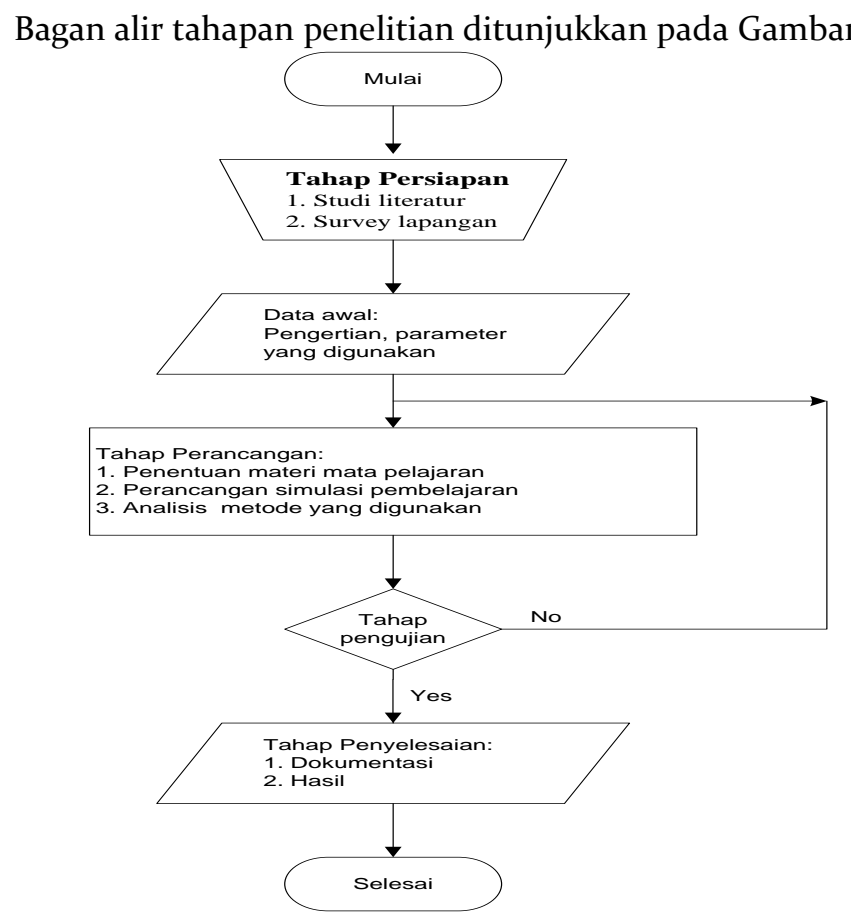

Gambar 1 Bagan Alir Tahapan Penelitian

Penelitian dilakukan di Kampus Universitas Prima Indonesia, Medan. Lokasi spesifik kegiatan penelitian antara lain :

1. Fakultas Teknik dan Ilmu Komputer, Universitas Prima Indonesia : survey lapangan dan pengumpulan data.

2. Perpustakaan : studi literatur penelitian-penelitian internal terdahulu.

3. Laboratorium Komputer : perancangan dan pembuatan aplikasi.

\section{HASIL DAN PEMBAHASAN}

Hasil yang didapatkan dari pelaksanaan pengabdian kepada masyarakat yang sasarannya guru-guru SMP Sawasta Assyuhada Medan yaitu; 
1. Hasil Non-Fisik adalah guru SMP Swasta Assyuhada Medan sangat berminat mendapatkan bimbingan membuat karya inovatif berupa simulasi media pembelajaran. Dari hasil evaluasi menunjukkan selama proses pelatihan peserta selain serius dan antusian mengikuti kegiatan pelatihan, juga peserta hadir 100\% dan aktif bertanya serta mengerjakan letihan-latihan yang diberikan satgas pelaksana. Dari evaluasi terhadap hasil akhir dapat disimpulkan bahwa 90\% (dari 15 peserta) telah memahami pengetahuan dan keterampilan tentang proses pembuatan laporan media pembelajaran sebagai karya inovatif. Setelah diberi pelatihan terjadi perubahan pandangan ke arah positif terhadap pentingnya membuat laporan media pembelajaran sebagai karya inovatif untuk Pengembangan Keprofesian Berkelanjuan. Dari hasil evaluasi terhadap proses dan hasil secara non-fisik setelah pelatihan ini dimungkinkan peserta mampu mengembangkan dan menularkan pengetahuan dan keterampilan kepada guru-guru lain di sekitar tempat tugas mereka;

2. Hasil Fisik yaitu produk berupa jenis-jenis simulasi yang merupakan karya inovatif. Berdasarkan hasil yang dicapai selama proses pelatihan dan setelah pelatihan yang meliputi keaktifan, antusiasme, dan kreativitas peserta dalam menghasilkan jenis-jenis Media Pembelajaran sebagai Karya Inovatif maka dapat dinyatakan bahwa kegiatan pelatihan bagi guru.

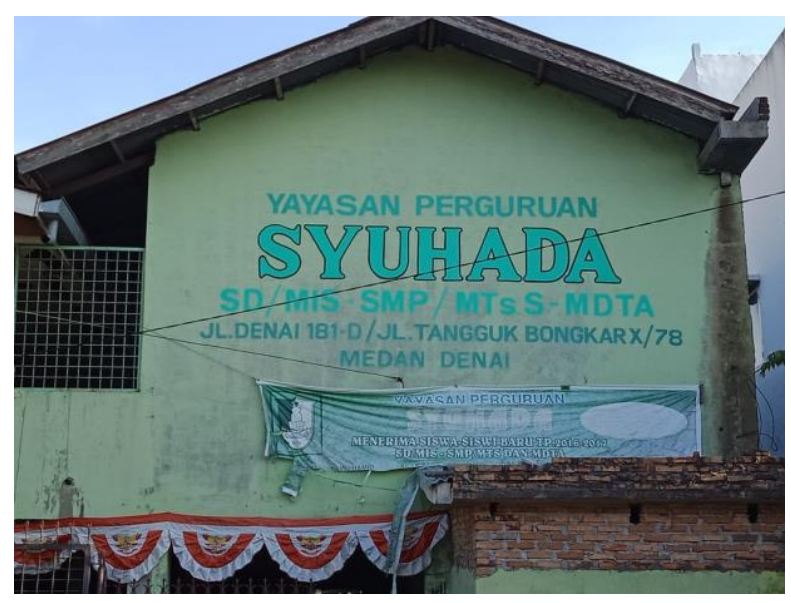

Gambar 2 Gedung Sekolah 
Fadhillah Azmi. Juanda Hakim Lubis. \& N P Dharshinni. Pelatihan Modul Ajar Robotika Visual Basic Di

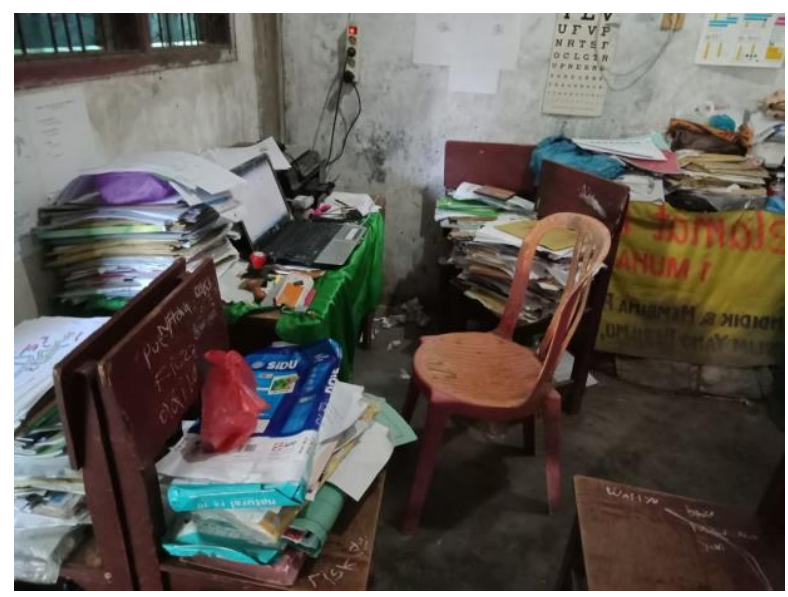

Gambar 3 Ruang Guru

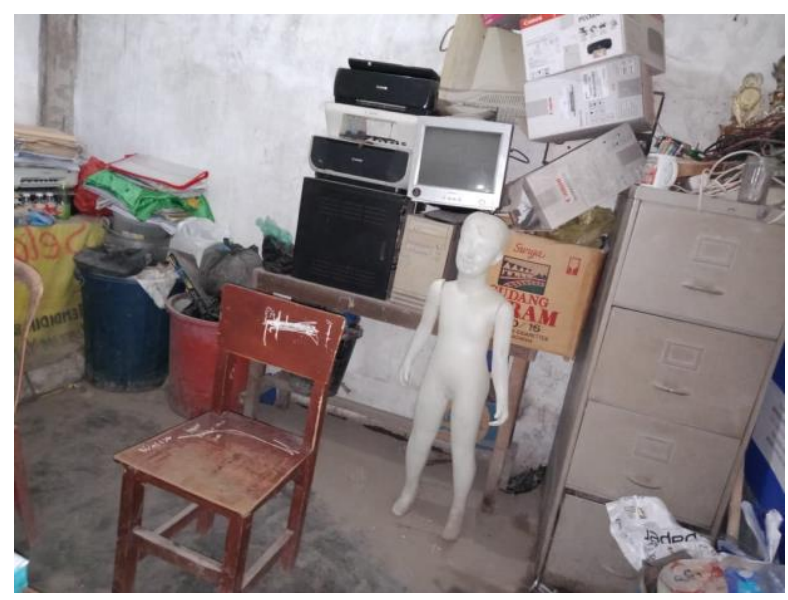

Gambar 4 Ruang Lab

\section{SIMPULAN}

Kegiatan pengabdian kepada masyarakat ini dianggap berhasil karena pada akhir kegiatan semua peserta pelatihan memiliki pengetahuan dan keterampilan praktis tentang pembuatan simulasi media pembelajaran sabagai karya inovatif untuk penerapan di mata pelajaran.

\section{DAFTAR PUSTAKA}

Achsin A. (2000). Media Pendidikan dalam Kegiatan Belajar Mengajar. Ujung Pandang. Penerbit IKIP Ujung Pandang

Anderson, R.H. (2002). Pemilihan dan Pengembangan

Media untuk Pembelajaran. Jakarta: Universitas Terbuka dan Pusat Antar Universitas di Universitas Terbuka.

Arsyad, Azhar. (2000). Media pengajaran. Jakarta: Raja Grafindo Persada.

Arsyad, Azhar. (2003). Media Pembelajara. Jakarta: PT

Raja Grafindo Persada. 
Azhar, Arsyad, (2003). Media Pembelajaran. Jakarta: PT Grafindo Persada.

Deprtemen Agama Republik Indonesia. (2010). Alquran dan Terjemahnya. Jakarta: Depag. RI

Deradjat, Zakiah. (2001). Ilmu Pendidikan Islam . Jakarta: Bumi Aksara, 1990.

Hamalik, Oemar. (2004). Media Pendidikan. Bandung: Citra Aditya Bakti.

Sanjaya, Wina. (2010). Perencanaan dan Desain Sistem Pembelajaran. Jakarta: Kencana Prenada Media Group. 